\title{
A Novel Technology for Minimizing the Synthesis Time of Nanostructured Powders in Planetary Mills
}

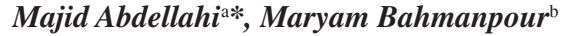 \\ ${ }^{a}$ Materials Engineering Department, Najafabad Branch, Islamic Azad University, Najafabad, Iran \\ ${ }^{\mathrm{b}}$ Mathematics Department, Sama Technical and Vocational Training College, \\ Khorasgan Branch, Islamic Azad University, Isfahan, Iran
}

Received: December 5, 2013; Revised: January 28, 2014

\begin{abstract}
A key objective in processing of nanostructured powders via high energy ball milling is to minimize the synthesis time. This paper presents the application of imperialist competitive algorithm (ICA) for optimization of milling parameters in order to minimize the synthesis time of nanostructured powders in planetary mills. At first a direct relationship between the inverse of the milling time and the power of the planetary mill was established, which allows the validation of theoretical models proposed in the literature for the energy transfer in milling devices and the comparison of milling equipment efficiencies. Afterwards based on the obtained relation, eight design parameters in milling, namely, number of balls, ball diameter, vial radius, vial height, ball diameter distribution coefficient, plate spinning rate, vial spinning rate and distance between the center of the plate and the center of the vial were optimized. Using these optimized variables in milling process the energy transferred to the raw materials was maximized or in the equivalent expression the synthesis time of nanostructured powders was minimized. At the end a test case was solved to demonstrate the effectiveness and accuracy of the proposed design. Computational results showed that the proposed optimization algorithm is quite effective and powerful in optimizing the planetary mills.
\end{abstract}

Keywords: nanostructured powders, milling, optimization, ICA algorithm

\section{Introduction}

Mechanical Alloying (MA) is a ball milling process where a powder mixture placed in a ball mill is subjected to high-energy collision from the balls. The process leads to repetitive plastic deformation, fracturing and cold welding of the powders. The prolonged milling of powder mixtures can lead to the formation of supersaturated solid solutions, (nonequilibrium) intermetallic compounds, or to the formation of stable or unstable carbides, borides, nitrides, silicides, etc ${ }^{1,2}$.

It is generally accepted that changing the milling parameters can enhance the energy input into the powder per unit time ${ }^{3,4}$, so building a mathematical model correlating the milling parameters with the syntheses time of nanostructured powders can be useful. The aim of constructing a model is to be able to design the mechanical alloying process and to predict the formation of the desired products in the least possible time by adjusting the milling parameters appropriately.

In the past, several studies have dealt with the dynamics and efficiency of planetary mills and their dependence on milling parameters, irrespective of the specific phenomena occurring during the mechanochemical process ${ }^{5-11}$. Burgio et al. ${ }^{12}$ have derived a set of kinematic equations to compute the velocity and acceleration of a ball in a planetary mill, and thereby, estimate the energy transferred to the powder particles.

*e-mail: info@abdellahi.net
In this work the model of Burgio et al. ${ }^{12}$ was chosen because it describes the energy supplied by a planetary mill using only analytical expressions without any numerical calculation so that it was possible to more easily compare the quantitative forecasts of the model with our observational data.

The optimization problem can be described as to find an argument $\mathrm{x}$ whose relevant cost $\mathrm{f}(\mathrm{x})$ is optimum, and it has been extensively used in many different situations such as industrial planning, resource allocation, scheduling, pattern recognition. Different methods have been proposed to solve the optimization problem ${ }^{13}$. Evolutionary algorithms, such as genetic algorithm ${ }^{14,15}$, particle swarm optimization ${ }^{16,17}$, taboo search ${ }^{18-20}$, ant colony optimization ${ }^{21-23}$, bees algorithm ${ }^{24-26}$, simulated annealing ${ }^{27,28}$, biogeography based optimization $^{29,30}$, firefly optimization ${ }^{31,32}$ and artificial bee colony ${ }^{33,34}$ are a set of algorithms that were suggested in the past decades for solving optimization problems in different branches of engineering. Imperialist Competitive Algorithm (ICA) is an algorithm introduced for the first time in 2007 by Atashpaz-Gargari and Lucas ${ }^{35}$ and used for optimizing inspired by the imperialistic competition and has a considerable relevance to several engineering applications.

ICA is a new and powerful optimization technique which has been never used in materials engineering. This study has provided new and powerful methodology in the optimization of planetary mills for minimizing the synthesis 
time of nanostructured powders in planetary mills. Based on proposed method, a full computer code was developed for optimal design of planetary mill and one test case is solved by it to illustrate the effectiveness and accuracy of the proposed algorithm. Results showed that the proposed method is very accurate, quick and economic method for optimal design of vial and ball in planetary mills.

\section{Problem Definition}

Figure 1 shows the schematic diagram of the planetary ball mill and the vial: indicating by $\mathrm{W}_{\mathrm{p}}$ and $\mathrm{W}_{\mathrm{v}}$ the absolute angular velocity of the plate of the mill and of one vial and by $R_{p}$ and $R_{v}$ the vectorial distances from the center of the mill to the center of the vial and from the center of the vial to its periphery ( vial radius), it can be shown the absolute velocity of one ball leaving the wall is given by:

$$
V_{b}=\left[\left(W_{p} R_{p}\right)^{2}+W_{v}^{2}\left(R_{v}-d_{b} / 2\right)^{2}\left(1-2 W_{v} / W_{p}\right)\right]^{1 / 2}
$$

the velocity of the ball with $\mathrm{d}_{\mathrm{b}}$ diameter, after the hits, equals that of the inner wall and can be expressed as follow:

$$
V_{S}=\left[\left(W_{p} R_{p}\right)^{2}+W_{v}^{2}\left(R_{v}-d_{b} / 2\right)^{2}+2 W_{p} W_{v} R_{P}\left(R_{v}-d_{b} / 2\right)\right]^{1 / 2}
$$

We have to consider now the mechanism of energy transfer. When the ball is thrown, it possesses the kinetic energy:

$$
E=1 / 2 m_{b} V_{b}^{2}
$$

After a short succession of hits, during which decreasing fractions of kinetic energy are released, the balls residual energy becomes:

$E=1 / 2 m_{b} V_{S}^{2}$ and the total energy released by the ball during the series of collision events is given by:

$$
\Delta E_{b}=E_{b}-E_{S}=-m_{b}\left[W_{v}^{3}\left(R_{v}-d_{b} / 2\right) / W_{p}+W_{p} W_{v} R_{p}\right]\left(R v-d_{b} / 2\right)
$$

With the assumption that the total energy transferred by the planetary mill per gram of reactant mixture and required to synthesis of nano-structure powders is a constant value, the Burgio model defines this amount of energy by the following expression:

$E_{t} / g=\frac{\left(N_{b} \varphi_{b} f_{b} K_{a} m_{b}\right)\left[W_{v}^{3}\left(R_{v}-d_{b} / 2\right) / W_{p}+W_{P} W_{v} R_{P}\right]\left(R_{v}-d_{b} / 2\right) t}{m_{c h}}=A(J / g)$

Where $N_{b}$ is the number of balls; $\phi_{b}$ is a parameter that accounts for the degree of filling of the vial; $f_{b}$ is the frequency with which the balls are launched against the opposite wall of the vial $\left(\mathrm{s}^{-1}\right) ; \mathrm{K}$ is a constant that accounts for the elasticity of collisions, and a value of 1 represents perfectly inelastic collisions; $\mathrm{m}_{\mathrm{ch}}$ is the mass of the powder charge; and $\mathrm{t}$ is the synthesis time measured (s).

\section{Imperialist Competitive Algorithm}

Figure 2 indicates the flowchart of the ICA. Like other evolutionary algorithms, ICA algorithm begins with an initial population (countries in the world). A number of the best countries (in optimization terminology, countries with the least cost) are chosen to be the imperialist states and the other countries form the colonies of these imperialists. All the colonies of initial countries are divided among the aforementioned imperialists based on their power. The power of each country, the compeer of fitness value in the genetic algorithm, is inversely proportional to its cost. The imperialist states together with their colonies form some empires $^{35}$.
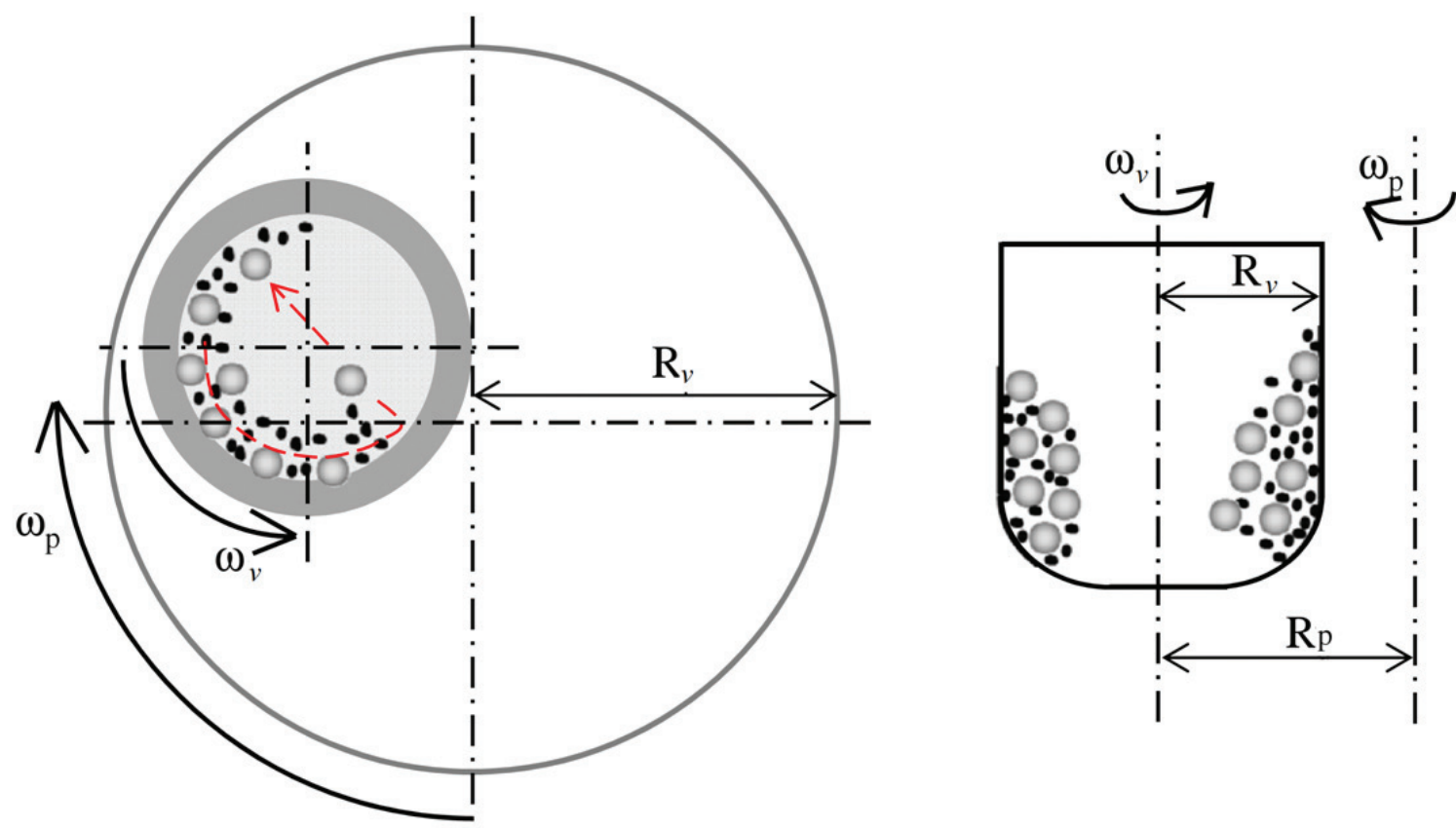

Figure 1. The schematic diagram of the planetary ball mill and the vial. 


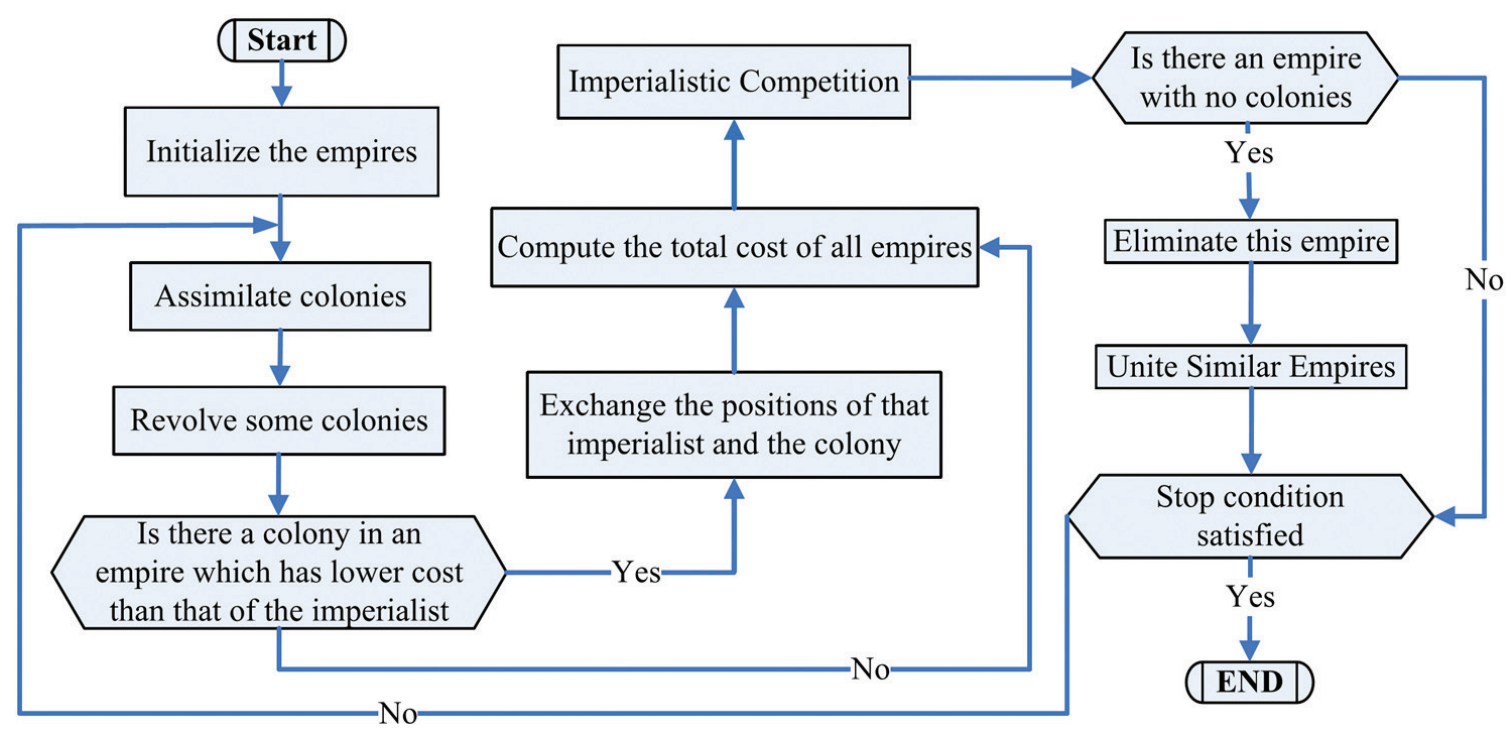

Figure 2. The flowchart of the ICA approach.

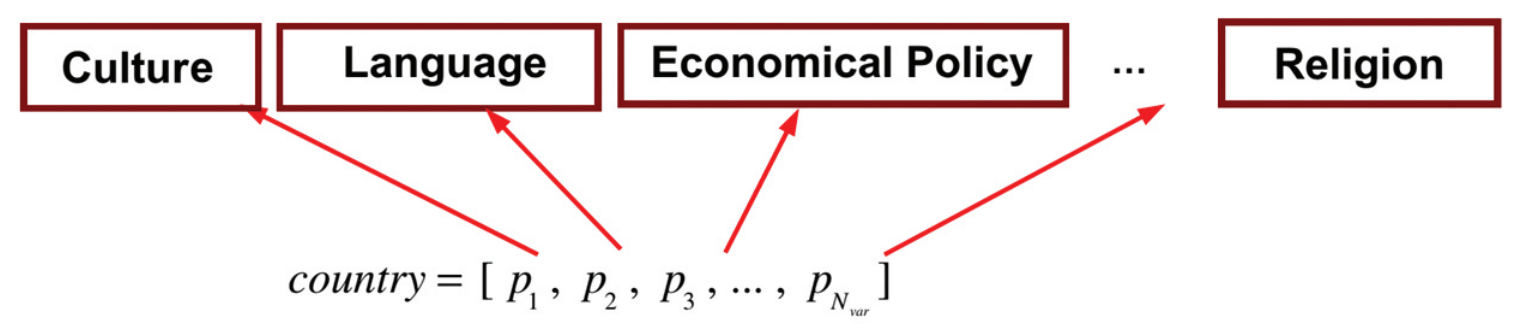

Figure 3. The candidate solutions of the problem, called country, consists of a combination of some socio-political characteristics such as culture, language and religion.

After dividing all colonies among imperialists, these colonies begin to move toward their relevant imperialist country. This movement is a simple model of assimilation policy which was pursued by some of the imperialist states. The total power of an empire depends on both the power of the imperialist country and the power of its colonies ${ }^{36}$. We will model this fact by defining the total power of an empire by the power of imperialist country plus a percentage of mean power of its colonies

\subsection{Initial empires creation}

Finding an optimal solution is the goal of optimization. We generate our countries which are the randomized solutions as population. An array of the problem variables is formed which is called Chromosome in genetic algorithm and country in this algorithm. In an $\mathrm{N}_{\text {var }}$-dimensional optimization problem a country is a $1 / \mathrm{N}_{\mathrm{var}}$ array which is defined as follows ${ }^{37}$ :

country $=\left[P_{1}, P_{2}, P_{3}, \ldots, P_{N_{\text {var }}}\right]$

Where $p_{i}$ s are the variables to be optimized. The variable values in the country are represented as floating point numbers. From the historical-cultural point of view, social-political characteristics of the country such as culture, language, and political structure are considered the components of that country. Figure 3 depicts the rendition of country using some of socio-political characteristics. The cost of a country is found by evaluating the cost function $\mathrm{f}$ at the variables $\left(P_{1}, P_{2}, P_{3}, \ldots, P_{N_{\text {var }}}\right)^{38}$. Then $\cos t=f($ country $)=f\left(P_{1}, P_{2}, P_{3}, \ldots, P_{N_{\text {var }}}\right)$

To start the optimization process, $\mathrm{N}_{\text {country }}$ is generated and $\mathrm{N}_{\text {imp }}$ most powerful members of this population are chosen as imperialists. The residual $\mathrm{N}_{\text {col }}$ countries are the colonies, each of which is a part of one of the above mentioned empires ${ }^{39}$.

To form the initial empires, the colonies are then divided among imperialists, based on their powers. That is the initial number of colonies of an empire should be directly proportionate to its power. To divide the colonies among imperialists proportionally, the normalized cost of an imperialist are defined by $C_{n}=c_{n}-\max \left\{c_{i}\right\}$ where $c_{n}$ is the cost of $\mathrm{n}^{\text {th }}$ imperialist and $C_{n}$ is its normalized cost. Finally, the normalized power for each imperialist is defined by ${ }^{13}$ :

$P_{n}=\frac{\left|C_{n}\right|}{\left|\sum_{i=1}^{N_{\text {inp }}} C_{i}\right|}$ 


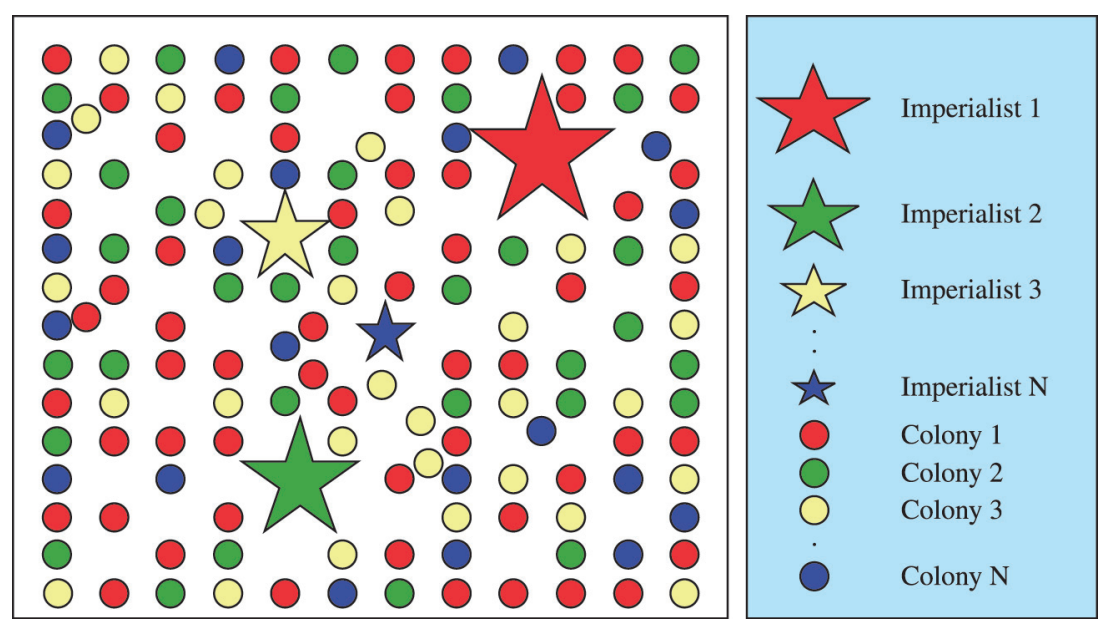

Figure 4. Generating the initial empires: The more colonies an imperialist possess, the bigger is its relevant ( $\star$ ) mark.

Then the initial number of colonies of the $\mathrm{n}^{\text {th }}$ empire will be: $N \cdot C_{n}=\operatorname{round}\left\{P_{n} \cdot N_{c}\right\}$; where $N \cdot C_{n}$ is the initial number of colonies of the $\mathrm{n}^{\text {th }}$ empire and $N_{c}$ is the number of initial colonies. To divide the colonies, $N \cdot{ }^{c} C_{n}$ of the colonies are randomly selected and given to the $\mathrm{n}^{\text {th }}$ imperialist. These colonies along with the $\mathrm{n}^{\text {th }}$ imperialist form the $\mathrm{n}^{\text {th }}$ empire.

Figure 4 presents the initial population of empires. As shown in this figure, more powerful empires have more colonies than weaker ones. In Figure 4 imperialist 1 is the strongest and has greater number of colonies ${ }^{40}$.

\subsection{Moving the colonies of an empire toward the imperialist(assimilation policy)}

Each colony that moves toward the imperialist by $\mathrm{x}$-units in the direction is the vector from colony to imperialist. This progress is indicated in Figure 5. $x$ will be a random variable with uniform distribution ${ }^{36}$.

$x=U(0, \beta \times d), \beta>1$

Where $d$ is the distance between colony and imperialist. $\beta$ causes the colony to get closer to the imperialist. To search more areas around the imperialist we consider a deviation in the direction of movement. In figure $\theta$ depicts this deviation which $\theta$ is a random number with uniform (or any proper) distribution ${ }^{40}$.

$$
\theta=U(-\gamma, \gamma)
$$

Where $\gamma$ is a parameter that adjusts the deviation from the original direction. Nonetheless, the values of band $\beta$ and $\gamma$ are freewill, in most of our implementation a value of about 2 for $\beta$ and about $\pi / 4$ (Rad) for $\gamma$, have resulted in good convergence of countries to the global minimum ${ }^{40}$.

\subsection{Exchanging positions of the imperialist and a colony}

While moving toward the imperialist, a colony may reach to a position with higher cost than that of imperialist. In such a case, the imperialist moves to the position of that colony and vice versa. Then algorithm continues by

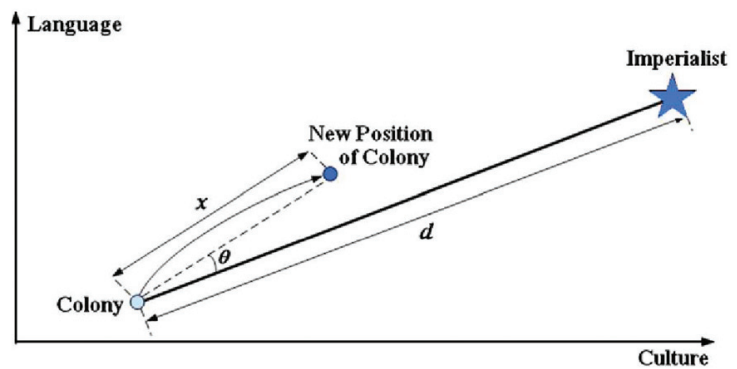

Figure 5. Moving colonies toward their relevant imperialist in a randomly deviated direction.

the imperialist in a new position and then colonies start moving toward this position ${ }^{39}$. Figure 6 a depicts the position exchange between a colony and the imperialist. In this figure the best colony of the empire is shown in a darker color. This colony has a lower cost than the imperialist. Figure $6 \mathrm{~b}$ shows the empire after swapping the position of the imperialist and the colony ${ }^{38}$.

\subsection{Computing total cost of an empire}

Total power of an empire depends on the power of imperialist and its colonies. But the main power in an empire is the power of its imperialist. So we define the total cost of the $\mathrm{n}^{\text {th }}$ empire by

$T C_{n}=\operatorname{Cost}($ imperialist $\mathrm{n})+\zeta \cdot \operatorname{Mean}\{\operatorname{Cost}($ colonies of empiren $)\}($

where $T C_{n}$ is the total cost of the $\mathrm{n}^{\text {th }}$ empire and $\zeta$ is a number between 0 and 1 . high value for $\zeta$ causes increase the role of the colonies in total power of an empire whereas low value for $\zeta$ causes the total power of the empire to be specified by only the imperialist power. Values between 0.05 and 0.1 for $\zeta$ in most of problems let to good solutions ${ }^{40}$.

\subsection{Imperialistic competition}

All empires are in competition with each other to take possession of colonies of other empires and control them. As a result, the power of the weaker empires gradually starts to 
diminish and the power of more powerful ones increases ${ }^{36}$. This model is shown in Figure 7. Here each empire which has more power has more chance to take possession of the weakest countries in the weakest empires. Victory in this competition is depending on the power of each empire. To achieve this goal, we find the possession probability of each empire based on its total power. The normalized total cost is

$$
N T C_{n}=T C_{n}-\max \left\{T C_{i}\right\}
$$

Where $T C_{n}$ and $N T C_{n}$ are respectively the total cost and the normalized total cost of $\mathrm{n}^{\text {th }}$ empire. Now we could be able to calculate the possession probability of each empire by:

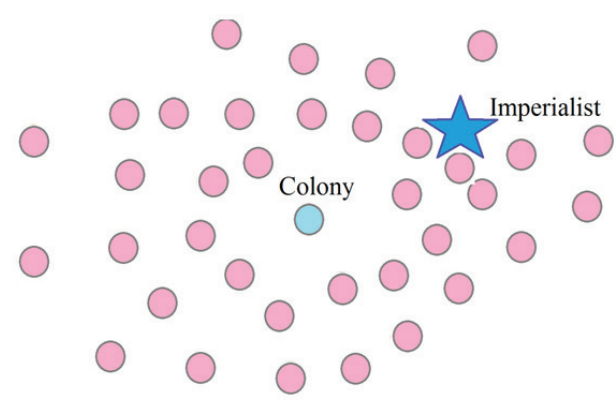

(a)

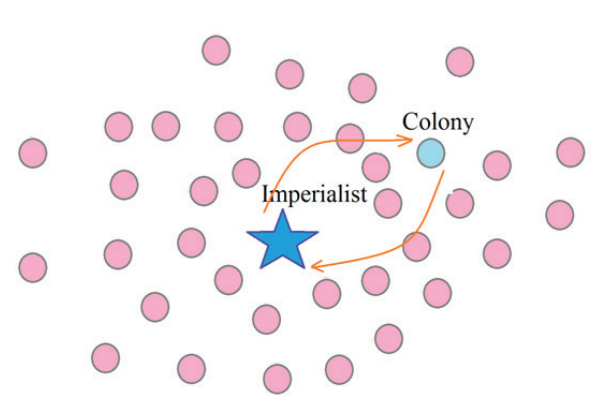

(b)

Figure 6. a: Exchanging the positions of a colony and the imperialist; b) The entire empire after position exchange.

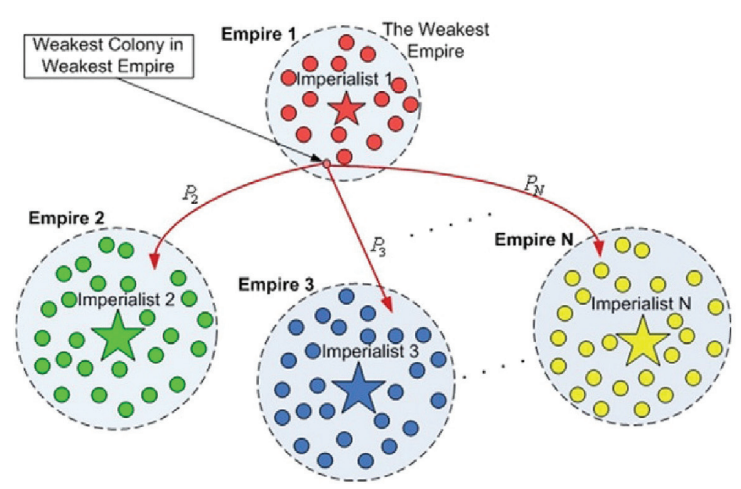

Figure 7. Imperialistic competition. The more powerful an empire has more probability to possess the weakest colony of the weakest empire.
$P_{p n}=\frac{\left|N T C_{n}\right|}{\left|\sum_{i=1}^{N_{i m p}} N T C_{i}\right|}$

To divide the mentioned colonies among empires vector $\mathrm{P}_{\mathrm{i}} \mathrm{s}$ formed as following:

$P=\left[P_{P 1}, P_{P 2}, P_{P 3}, \ldots, P_{P N_{\text {var }}}\right]$

Then the vector $\mathrm{R}$ with the same size as $\mathrm{P}$ whose elements are uniformly distributed random numbers is created $^{41}$

$R=\left[r_{1}, r_{2}, r_{3}, \ldots, r_{\text {Nimp }}\right] r_{1}, r_{2}, r_{3}, \ldots, r_{\text {Nimp }}=U(0,1)$

Then vector $\mathrm{D}$ is generated by subtracting $\mathrm{R}$ from $\mathrm{P}$. Referring to vector D the mentioned colony (colonies) is handed to an empire whose relevant index in D is maximized.

When an empire loses all its colonies, it is assumed to be collapsed. In this model implementation where the powerless empires collapse in the imperialistic competition, the corresponding colonies will be divided among the other empires ${ }^{42}$.

\subsection{Revolution}

A revolution is the terminology of ICA to describe a swift alteration in a part of countries' socio-political characteristics. Revolution process has an essential character which can be useful in escaping the local optima. In ICA, the percentage of colonies in an empire which will experience revolution procedure is demonstrated by revolution rate.

\subsection{Eliminating the powerless empires}

Feeble empires will collapse in the imperialistic competition and their colonies will be divided among other empires. To model this process, we assume an empire has been collapsed and remove it when it loses all of its colonies.

\subsection{Convergence}

After a certain time all the empires except the strongest one will removed and all the colonies will be under control of this single empire ${ }^{43}$. In such a situation we stop the algorithm. In this ideal new world all the colonies will have the same positions and same costs and they will be controlled by an imperialist with the same position and cost as themselves. The main steps in algorithm are summarized in the pseudo code shown in Figure 8.

\section{Imperialist competitive algorithm settings}

\subsection{Cost function}

From section 2 it was concluded that the milling time is dependent on the following variables:

$\Delta E_{b}, m_{c h}, N_{b}, \varphi_{b}, f_{b}, K_{a}, m_{b}, R_{v}, d_{b}, W_{p}, W_{v}, R_{P}$

On the other hand ${ }^{12,44}$ :

$\varphi_{b}=1-\left(\frac{d_{b}^{3} N_{b}}{\pi R_{v}^{2} H_{v}}\right)^{\varepsilon}$ 


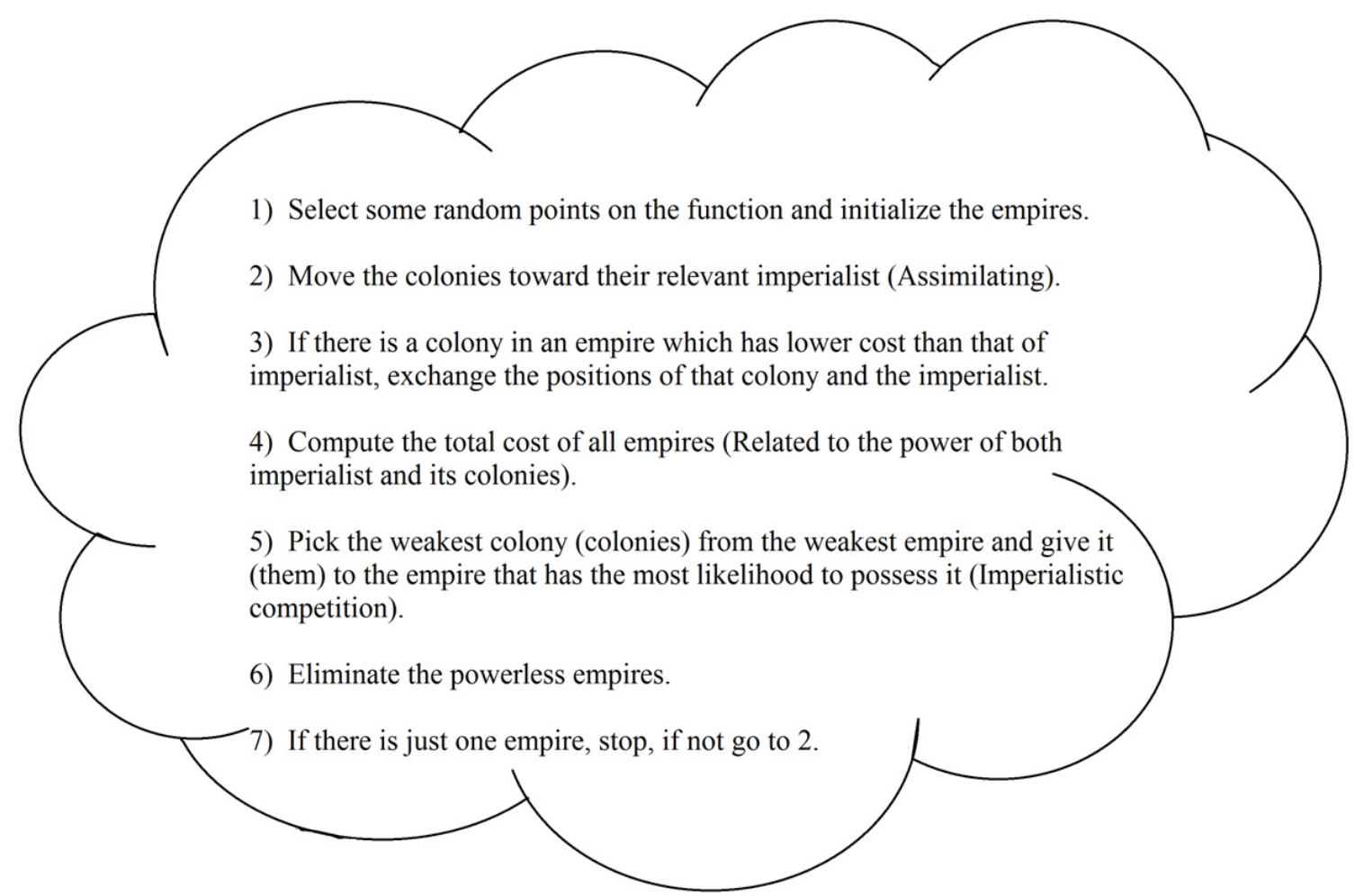

Figure 8. Pseudo code of the Imperialistic Competitive Algorithm.

$f_{b}=\frac{K\left(W_{p}-W_{v}\right)}{2 \pi}$

$m_{b}=\frac{\pi \rho_{b} d_{b}^{3}}{6}$

Where $H_{\mathrm{v}}, \rho_{\mathrm{b}}$ are respectively the height of the vial and the density of balls. $K$ is a proportionality constant and is approximately equal to unity ${ }^{44}$ and $\varepsilon$ is a parameter called ball diameter distribution coefficient depending on the balls diameter.

Using Equations 17-19, formula (6) can be rewritten as:

$$
t=\frac{12}{A p_{b} K_{a} K} \times m_{c h} \times \frac{1}{-N_{b}\left(1-\left(\frac{d_{b}^{3} N_{b}}{\pi R_{v}^{2} H_{v}}\right)^{\varepsilon}\right)\left(W_{p}-W_{v}\right)\left(d_{b}^{3}\right)\left(W_{v}^{3}\left(R_{v}-d_{b} / 2\right) / W_{p}+W_{P} W_{v} R_{P}\right)\left(R_{v}-d_{b} / 2\right)}
$$

or

$t=B \times m_{c h} \times f$

Which $B$ is constant depending on density of balls, elastic and inelastic collisions as well as the heat released by the reactions between the raw materials; $m_{c h}$ is the mass of the powder charge which is determined by ball to powder weight ratio (BPR); and $f$ is the cost function of the problem so that by minimizing the $f$, the synthesis time is also minimized.

Therefore, in such a scenario, all parameters including $N_{b}, d_{b}, R_{v}, H_{v}, \varepsilon, W_{p}, W_{v}, R_{p}$ play a fundamental role and they have to be optimized in order to achieve the minimum synthesis time or best operational performance of milling process.
To use the ICA to solve this problem, at first a proper definition of a country should be expressed. As noted before, the country is a set of unknown parameters of the problem. In this problem a country includes eight parameters as following:

Country $=\left[N_{b}, d_{b}, R_{v}, H_{v}, \varepsilon, W_{p}, W_{v}, R_{p}\right]$

To start the algorithm a collection of random solutions (random countries) is generated. The costs of all countries are calculated and some of those with least cost values are selected to be the imperialists of the algorithm. The remaining countries are divided among these imperialists as explained in Section3. After forming the initial empires, the assimilation is used to evolve the poor countries in each of the empires. After assimilating all of the colonies by imperialists in each empire, revolution is accomplished in some of the countries. Consequently some countries move to some positions that were not attainable by the assimilation process. After assimilation and revolution, the cost of each colony is calculated in its new position. Some of the colonies in each empire might have achieved to better positions than the imperialist itself. Here the imperialist is substituted by the best colony in the empire (The colony with the least value of cost function). The total cost of empires is calculated as in Equation 8 and then imperialistic competition starts and a colony of poor empires are attracted by another one. The continuation of these processes converge the algorithm and it might achieve to the global minimum of the cost function. 


\subsection{ICA parameters}

Table 1 shows the ICA parameters used in this study. It should be noted that different values for the ICA parameters were tested in this study, however lowest value for cost function $f$ was generated by the values in Table 1 .

\section{Results and Discussion}

\subsection{Minimum value of cost function}

Figure 9 shows all solutions (all countries) to optimize the milling parameters. As shown in this figure, for all solutions the $d_{b}, R_{v}, H_{v}$ variables have low values whereas the $W_{p}, W_{v}$ variables have high values indicating that the size vial should be small whereas the energy should be large.

Figure 10 shows the convergence of the ICA to the optimal solution. As is clear ICA has achieved to the optimal values of $\left[N_{b}, d_{b}, R_{v}, H_{v}, \varepsilon, W_{p}, W_{v}, R_{p}\right]$ in about 435 decades (iteration). A sharp decrease in the cost function can be observed in the first 10 decades. The variation of the cost function becomes very small when the iteration reaches more than 10 decades. The minimum cost function is found to be 0.0391 after 435 decades. In Table 2 the results of optimization is presented for the object of minimum cost function. As is clear from this table $W_{v}=1.32 W_{p}$ meaning that the vial spinning rate should be higher than the plate spinning rate (in the opposite direction). On the other hand, $\varepsilon=0.398$ which means that the ball size distribution is close to $40 \%$. The number of ball categories, $s$, is thus:

$$
\left.\begin{array}{l}
N_{b}=8.97 \approx 9 \\
\varepsilon \approx 0.4
\end{array}\right\} \Rightarrow s=\text { integer }(0.4 \times 9)=3
$$

According to balls size and above interpretation one can wright:

$$
\left.\begin{array}{l}
\begin{array}{l}
d_{b}=12 \mathrm{~mm} \\
N_{b}=9 \\
s=3
\end{array}
\end{array}\right\} \Rightarrow(9 \times 12 \mathrm{~mm})=\overbrace{(3 \times 10 \mathrm{~mm})}^{1}+\overbrace{(3 \times 12 \mathrm{~mm})}^{2}+\overbrace{(3 \times 14 \mathrm{~mm})}^{3}
$$

So we can say that the size of balls used in proposed design should be $10 \mathrm{~mm}, 12 \mathrm{~mm}$ and $14 \mathrm{~mm}$ for the maximum energy transfer to the raw materials.

\subsection{Comparison to other optimization techniques}

The ability of the ICA to optimize the synthesis time of nanostructured powders in planetary mills is compared to the two existing advanced optimization algorithms: Artificial Bee Colony $(\mathrm{ABC})$ and Biogeography Based Optimization (BBO). As is clear, the best solution for $\mathrm{ABC}$ and $\mathrm{BBO}$ algorithms is 0.065 (Figure 11a) and 0.0.53 (Figure 11b), respectively. This means that the ICA algorithm is more powerful than other ones to minimize the cost function $f$ or synthesis time of nanopowders in planetary mills. (Table 3)

\subsection{Case Study}

\subsubsection{Materials and methods}

To evaluate the efficiency of the algorithm and obtained parameters a case study was conducted. To this end, titanium dioxide $\left(\mathrm{TiO}_{2}\right.$, Merck, 99\%, 1-3 $\mu \mathrm{m}$ ), aluminum ( $\mathrm{Al}$, Merck,
Table 1. Parameters of ICA approach.

\begin{tabular}{lc}
\hline \multicolumn{1}{c}{ ICA parameters } & Value \\
\hline Number of countries & 100 \\
Number of initial imperialists & 5 \\
Number Of decades(iteration) & 500 \\
Revolution rate & 0.3 \\
$\beta$ & 0.25 \\
$\gamma$ & 0.5 \\
\hline
\end{tabular}

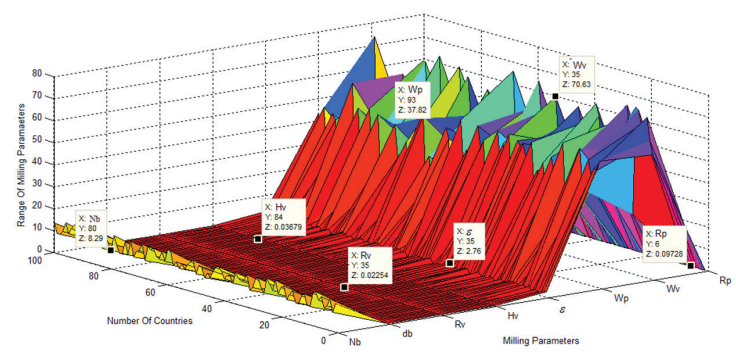

Figure 9. All solutions (all countries) to optimize the milling parameters.

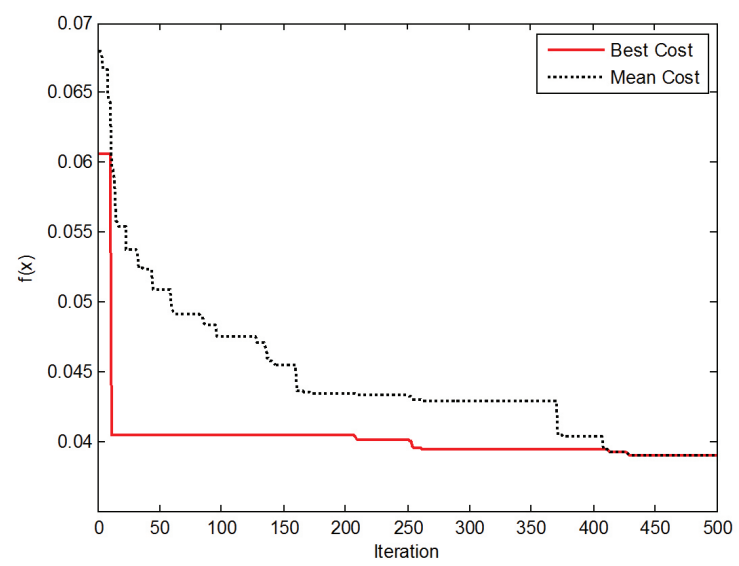

Figure 10. Convergence of the ICA to the optimal solution.

99\%, 10-50 $\mu \mathrm{m}$ ), boron oxide ( $\mathrm{B}_{2} \mathrm{O}_{3}$, Merck, $99.99 \%$, 5-100 $\mu \mathrm{m})$ were mixed according to reaction 1 :

$10 \mathrm{Al}+3 \mathrm{TiO}_{2}+3 \mathrm{~B}_{2} \mathrm{O}_{3}=3 \mathrm{TiB}_{2+} 5 \mathrm{Al}_{2} \mathrm{O}_{3}$

A planetary ball mill (Model PM 2400) with the stainless steel vials and balls was used for perform the experiments. The ball to powder weight ratio (BPR) was considered 15:1 and $m_{c h}$ was determined based on the value of BPR as well as density of balls. The phase identification of the milled samples was examined by X-ray diffraction (XRD) with $\mathrm{CuK} \alpha$ radiation at $30 \mathrm{kV}$ and $25 \mathrm{~mA}$. Mean grain size was calculated on the basis of Rietveld refinement method $^{45}$ by using of X'Pert high score plus software (developed by PANalytical BV Company, Almelo, the Netherlands, and version $2.2 b$ ).

In the first experiment with the laboratory conditions (system 1) the milling parameters were adjusted based on the 
Table 2. Milling parameters optimized values in planetary mill.

\begin{tabular}{|c|c|c|}
\hline Symbol & Milling parameters & Optimized values \\
\hline $\mathrm{N}_{\mathrm{b}}$ & Number of balls & $8.97 \sim 9$ \\
\hline$d_{b}$ & Balls diameter $(\mathrm{m})$ & 0.012 \\
\hline $\mathrm{R}_{\mathrm{v}}$ & Vial radius $(\mathrm{m})$ & 0.047 \\
\hline $\mathrm{H}_{\mathrm{v}}$ & Vial height (m) & 0.082 \\
\hline$\varepsilon$ & Ball size distribution coefficient & 0.398 \\
\hline $\mathrm{W}_{\mathrm{p}}$ & Velocity of the plate $\left(\right.$ rad.s $\left.{ }^{-1}\right)$ & 58.75 \\
\hline $\mathrm{W}_{\mathrm{v}}$ & Velocity of vial $\left(\mathrm{rad} . \mathrm{s}^{-1}\right)$ & 77.99 \\
\hline $\mathrm{R}_{\mathrm{p}}$ & distance between the center of the plate and the center of the vial (m) & 0.136 \\
\hline
\end{tabular}

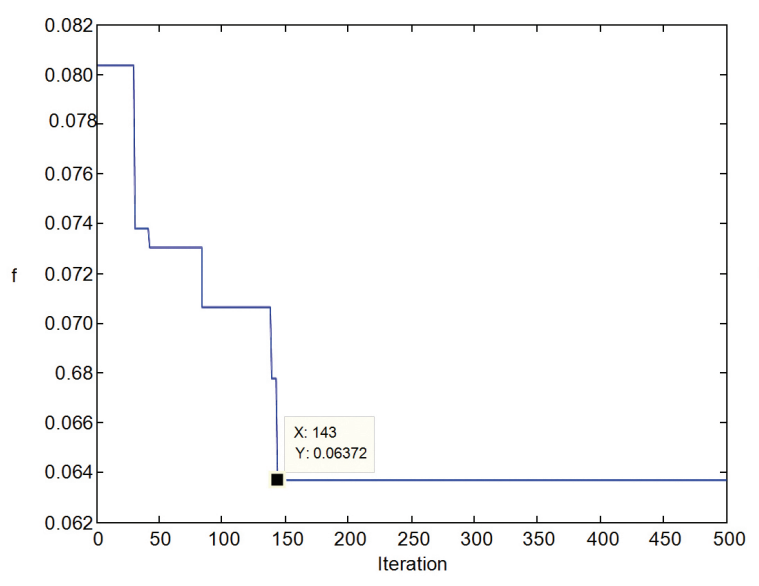

(a)

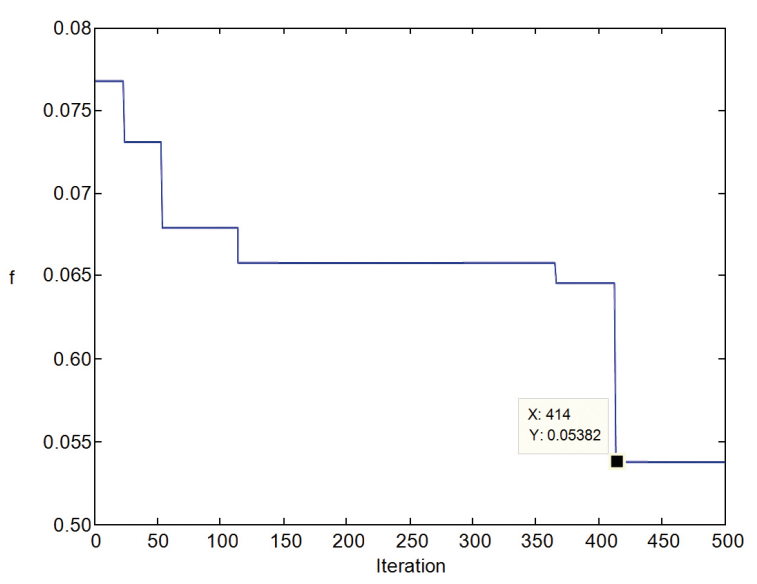

(b)

Figure 11. Convergence of the a) $\mathrm{ABC}$ and b) $\mathrm{BBO}$ algorithms to the optimal solution.

Table 3. Comparison of the abilities of the ICA, ABC and BBO algorithms.

\begin{tabular}{rccc}
\hline Algorithm & ICA & ABC & BBO \\
\hline Best cost function & 0.039 & 0.063 & 0.053 \\
\hline
\end{tabular}

values of Table 4. Figure 12a depicts the XRD patterns of the milled powders under the terms of System 1. As is clear there is no change in the reflections of the starting materials up to 105 min of milling except the peak broadening which it is attributed to the crystallite size refinement. By increasing the milling time to $120 \mathrm{~min}$, all peaks of initial powder mixture ( $\mathrm{Al}, \mathrm{B}_{2} \mathrm{O}_{3}$ and $\mathrm{TiO}_{2}$ ) were disappeared. On the other hand, $\mathrm{Al}_{2} \mathrm{O}_{3}$ and $\mathrm{TiB}_{2}$ were formed in the range 105-120 min of milling. Figure $12 \mathrm{~b}$ shows the XRD patterns of the milled powders related to proposed design (system 2). Here the formation time of $\mathrm{Al}_{2} \mathrm{O}_{3}$ and $\mathrm{TiB}_{2}$ was reduced to $90 \mathrm{~min}$ of milling. This means that the milling energy in system 1 is less than one in system 2 and therefore this system needs more milling times for the formation of products in comparison with system 2 .

Table 5 shows the mean grain size of milled powders for both systems. In the different conditions of milling, the mean grain size of milled powders in system 2 is smaller
Table 4. Milling parameters non-optimized values in planetary mill.

\begin{tabular}{|c|c|c|c|c|}
\hline $\begin{array}{c}\text { Milling } \\
\text { parameters }\end{array}$ & \multicolumn{4}{|c|}{ Laboratory values } \\
\hline $\mathrm{N}_{\mathrm{b}}$ & \multicolumn{4}{|c|}{13} \\
\hline $\mathrm{d}_{\mathrm{b}}$ & $\begin{array}{c}0.003 \mathrm{~m} \\
\text { (4 balls) }\end{array}$ & $\begin{array}{c}0.008 \mathrm{~m} \\
\text { (4 balls) }\end{array}$ & $\begin{array}{c}0.012 \mathrm{~m} \\
\text { (3 balls) }\end{array}$ & $\begin{array}{c}0.014 \mathrm{~m} \\
(2 \text { balls })\end{array}$ \\
\hline $\mathrm{R}_{\mathrm{v}}$ & \multicolumn{4}{|c|}{$0.035 \mathrm{~m}$} \\
\hline $\mathrm{H}_{\mathrm{v}}$ & \multicolumn{4}{|c|}{$0.072 \mathrm{~m}$} \\
\hline $\mathrm{W}_{\mathrm{p}}$ & \multicolumn{4}{|c|}{$58.63 \mathrm{rad} . \mathrm{s}^{-1}$} \\
\hline $\mathrm{W}_{\mathrm{v}}$ & \multicolumn{4}{|c|}{$73.29 \mathrm{rad} . \mathrm{s}^{-1}$} \\
\hline $\mathrm{R}_{\mathrm{p}}$ & \multicolumn{4}{|c|}{$0.114 \mathrm{~m}$} \\
\hline
\end{tabular}

than those in system 1 . This difference is due to the more milling energy during milling in system 2 .

In addition to the above, it should be noted that in many highly exothermic powder mixtures, ball milling can generate mechanically induced self-sustaining reactions (MSRs). The MSR is ignited when the powder reaches a well defined critical state ${ }^{45}$. Once started, the reaction propagates through the powder charge as a combustion process. Considering that the reaction (1) occurs in MSR mode ${ }^{46}$, the heat released from reaction (1) should be investigated in both systems. Figure 13 shows the nanostructured powders peaks 


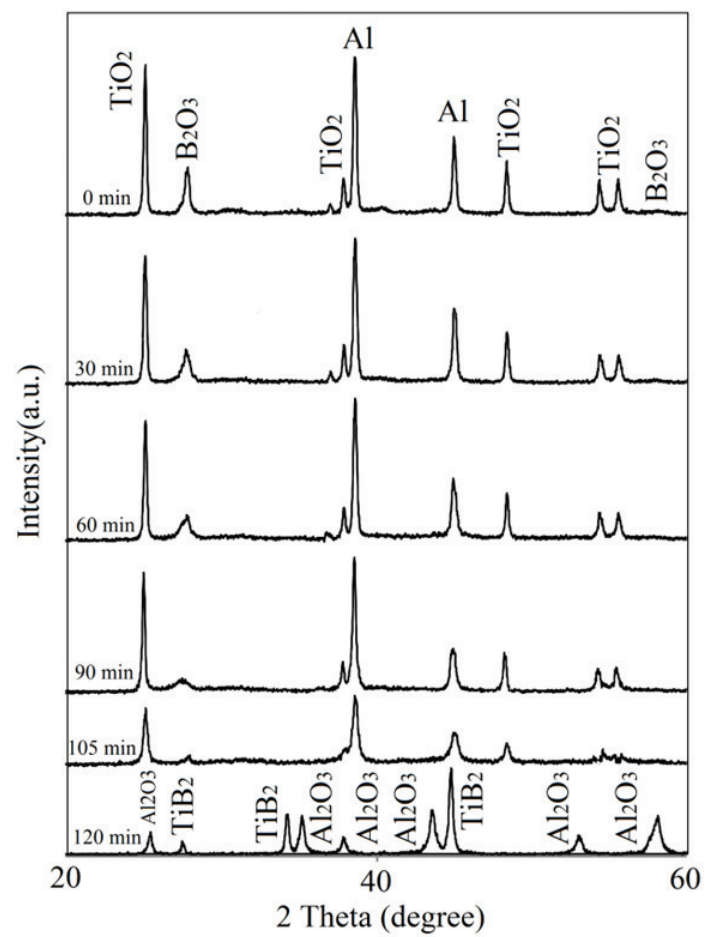

(a)

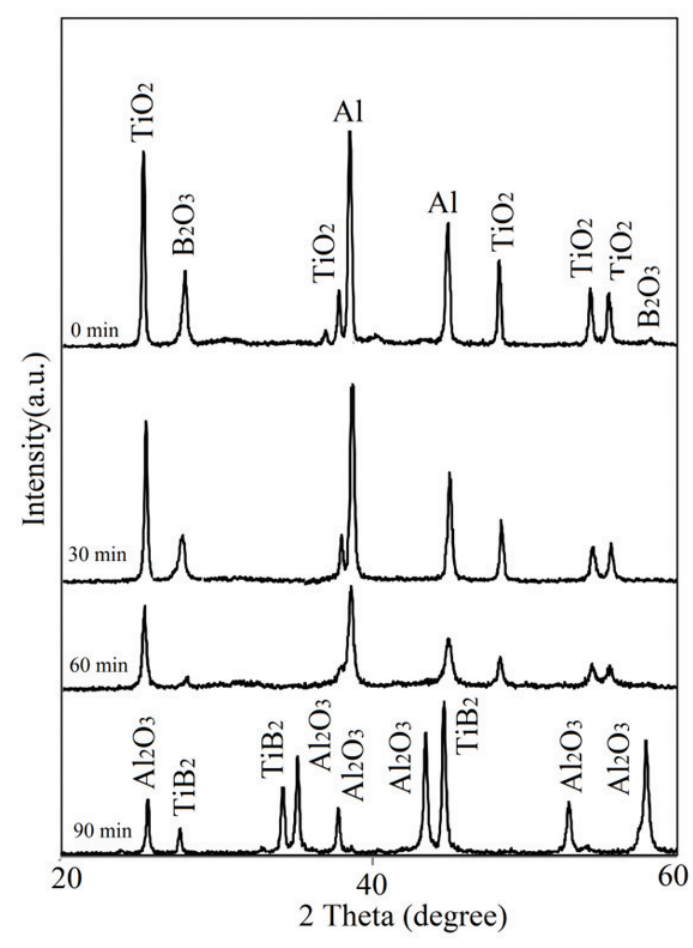

(b)

Figure 12. XRD patterns of $\mathrm{Al}, \mathrm{B}_{2} \mathrm{O}_{3}$ and $\mathrm{TiO}_{2}$ milled powders in a) system 1 ; b) system 2 .

Table 5. Mean grain size of both systems in various milling times.

\begin{tabular}{|c|c|c|c|c|c|c|}
\hline \multirow{3}{*}{$\begin{array}{l}\text { Milling time } \\
\qquad(\mathrm{min})\end{array}$} & \multicolumn{6}{|c|}{ Mean grain size (nm) } \\
\hline & \multicolumn{3}{|c|}{ System 2} & \multicolumn{3}{|c|}{ System 1} \\
\hline & $\mathrm{TiO}_{2}$ & $\mathrm{~B}_{2} \mathrm{O}_{3}$ & Al & $\mathrm{TiO}_{2}$ & $\mathbf{B}_{2} \mathbf{O}_{3}$ & Al \\
\hline 30 & 51 & 44 & 68 & 56 & 57 & 74 \\
\hline 60 & 45 & 37 & 53 & 51 & 46 & 60 \\
\hline \multirow[t]{2}{*}{90} & & \multicolumn{2}{|r|}{$\mathrm{TiB}_{2}$} & 44 & 37 & 46 \\
\hline & & \multicolumn{2}{|r|}{49} & & & \\
\hline 105 & & \multicolumn{2}{|r|}{-} & 36 & 30 & 31 \\
\hline \multirow[t]{2}{*}{120} & & \multirow{2}{*}{\multicolumn{2}{|c|}{-}} & \multirow{2}{*}{\multicolumn{2}{|c|}{47}} & \\
\hline & & & & & & 42 \\
\hline
\end{tabular}

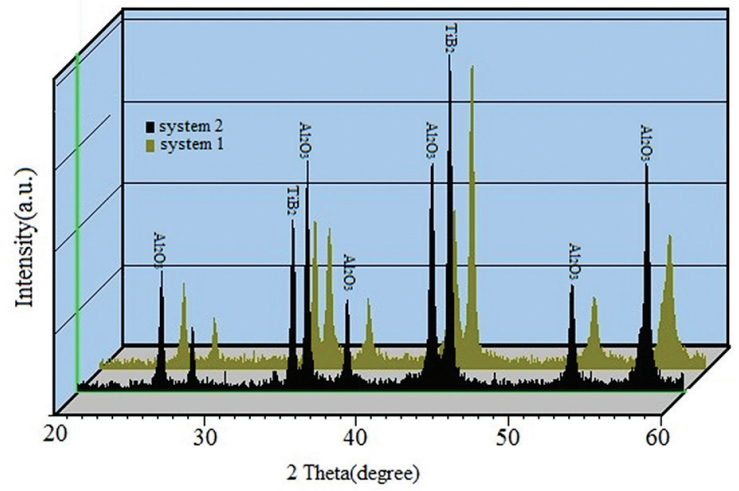

Figure 13. comparison of the heat released resulted from MSR mode in both systems. for system (1) and (2), immediately after ignition (90 min and 120 min for system 2 and system 1 , respectively). As is clear from this figure, the intensity peaks in system 2 are more than those in system 1 . This can be explained based on the Table 5 values, so that immediately after the formation of the products (immediately after ignition), the crystallite size has been increased in both systems. In other words, heat released from reaction 1 in system 2 caused by ignition, is more than one in system 1 leading to the formation of larger grains of products (immediately after ignition) in system 2 and hence more peaks intensity as shown in Figure 13. For further explanation, one can say that the more milling energy in system 2 leads to the reaction (1) occurs faster and therefore less heat is transferred to the environment in comparison with system 1 . 


\section{Conclusion}

Planetary mill design can be a complex task, and advanced optimization tools are useful to identify the best planetary mill for a specific duty. In this paper, a solution method of the planetary mill design optimization problem was proposed based on the utilization of an imperialist competitive algorithm. Based on proposed method, a full computer code was developed and one test case was solved by it. Based on all of the solutions obtained by ICA algorithm in order to minimizing the synthesis time of nanostructured powders, the vial size should be small whereas the energy transferred to the raw materials should be large. Result showed that by applying the optimized

\section{References}

1. Trapp J and Kieback B. Solid-state reactions during high-energy milling of mixed powders. Acta Materialia. 2013; 61(1):310320. http://dx.doi.org/10.1016/j.actamat.2012.09.061

2. Surianarayana C. Recent Developments In Mechanical alloying. Reviews on Advanced Materials Science. 2011; 18:203-211.

3. Zakeri M and Rahimipour MR. Effect of cup and ball types on alumina-tungsten carbide nanocomposite powder synthesized by mechanical alloying. Advanced Powder Technology. 2012; 23(1):31-34. http://dx.doi.org/10.1016/j.apt.2010.12.001

4. Budin S, Almanar IP, Kamaruddin S, Maideen NC and Zulkifli AH. Modeling of vial and ball motions for an effective mechanical milling process. Journal of Materials Processing Technology. 2009; 209(9):4312-4319. http://dx.doi. org/10.1016/j.jmatprotec.2008.11.016

5. Jiang X, Trunov MA, Schoenitz M, Dave RN and Dreizin EL. Mechanical alloying and reactive milling in a high energy planetary mill. Journal of Alloys and Compounds. 2009: 478(12): 246-251. http://dx.doi.org/10.1016/j.jallcom.2008.12.021

6. Joardar J, Pabi SK and Murty BS. Estimation of entrapped powder temperature during mechanical alloying, Scripta Materialia. 2004; 50(9): 1199-1202. http://dx.doi.org/10.1016/j. scriptamat.2004.02.011

7. Magini M and Iasonna A. Energy transfer in mechanical alloying (Overreview). Materials Transactions. 1995;36(2)123-133.

8. Schilz J. Internal Kinematics of Tumbler and Planetary Ball Mills: A Mathematical Model for the Parameter Setting. Materials Transactions. 1998; 39(11):1152-1157.

9. Delogu F, Mulas G, Schiffini L and Cocco G. Mechanical work and conversion degree in mechanically induced processes. Materials Science and Engineering: A. 2004; 382(1-2): 280287. http://dx.doi.org/10.1016/j.msea.2004.05.047

10. Rojac T, Kosec M, Malič B and Holc J. The application of a milling map in the mechanochemical synthesis of ceramic oxides. Journal of the European Ceramic Society. 2006; 26(16): 3711-3716. http://dx.doi.org/10.1016/j. jeurceramsoc.2005.11.013

11. Magini M, Iasonna A and Padella F. Ball milling: an experimental support to the energy transfer evaluated by the collision model. Scripta Materialia. 1996; 34(1):13-19. http:// dx.doi.org/10.1016/1359-6462(95)00465-3

12. Burgio N, Iasonna A, Magini M, Martelli S and Padella F. Mechanical alloying of the Fe-Zr system: correlation between input energy and end products. IL Nuovo Cimento D. 1991; 13(4):459-476. http://dx.doi.org/10.1007/BF02452130 parameters in planetary mill the formation time of $\mathrm{Al}_{2} \mathrm{O}_{3}$ and $\mathrm{TiB}_{2}$ was reduced to $90 \mathrm{~min}$ of milling. This means that the milling energy in laboratory system is less than one in optimal system and therefore this system needs more milling times for the formation of products in comparison with optimal system. The ability of the ICA to optimize the synthesis time of nanostructured powders in planetary mills was compared to the two existing advanced optimization algorithms. Results showed that the ICA algorithm is more powerful than other ones to minimize the cost function $f$. The algorithm proposed here can help the manufacturer and engineers to optimize all types of mills in engineering applications.

13. Karami A, Rezaei E, Shahhosseni M and Aghakhani M. Optimization of heat transfer in an air cooler equipped with classic twisted tape inserts using imperialist competitive algorithm. Experimental Thermal and Fluid Science. 2012; 38:195-200. http://dx.doi.org/10.1016/j. expthermflusci.2011.12.007

14. Wu CL and Chau KW. A flood forecasting neural network model with genetic algorithm. International Journal of Environment and Pollution. 2006; 28(3-4):261-273. http:// dx.doi.org/10.1504/IJEP.2006.011211

15. Muttil N and Chau KW. Neural network and genetic programming for modeling coastal algal blooms, International Journal of Environment and Pollution . 2006; 28(3-4): 223-238. http://dx.doi.org/10.1504/IJEP.2006.011208

16. Kennedy J and Eberhart RC. Particle swarm optimization. In: Proceedings of IEEE International Conference on Neural Networks; 1995. p. 1942-1948. http://dx.doi.org/10.1109/ ICNN.1995.488968

17. Lei K, Qiu Y and He Y. A new adaptive well-chosen inertia weight strategy to automatically harmonize global and local search ability in particle swarm optimization. In: International Symposium on Systems and Control in Aerospace and Astronautics; 2006. p. 977-980.

18. De Werra D and Hertz A. Tabu search techniques: a tutorial and an application to neural networks. Or Spektrum. 1989; 11(3):131-141. http://dx.doi.org/10.1007/BF01720782

19. Hertz A. Finding a feasible course schedule using tabu search. Discrete Applied Mathematics. 1992; 35(3):255-270. http:// dx.doi.org/10.1016/0166-218X(92)90248-9

20. Battiti R. and Tecchiolli G. The Reactive Tabu Search, Department of Mathematics. Trento: University of Trento; 1992.

21. Parpinelli RS, Lopes HS and Freitas AA. Data mining with ant colony optimization algorithm. IEEE Transactions on Evolutionary Computation. 2002; 6:321-332. http://dx.doi. org/10.1109/TEVC.2002.802452

22. Blum C and Sampels M. Ant colony optimization for FOP shop scheduling: a case study on different pheromone representations. In: Proceedings of the 2002 congress on Evolutionary Computation; 2002; Honolulu, USA; 2002. p. $1558-1563$.

23. Ying $\mathrm{W}$ and Jianying $\mathrm{X}$. Ant colony optimization for multicast routing. In: The 2000 IEEE Asia-Pacific Conference on Circuits and Systems; 2000; Tianjin, China; 2000.

24. Pham DT, Ghanbarzadeh A, Koç E and Otri S. Application of the Bees algorithm to the training of radial basis function networks for control chart pattern recognition. In: Proceedings 
5th CIRP International Seminar on Intelligent Computation in Manufacturing Engineering (CIRP ICME '06); 2006; Ischia, Italy; 2006.

25. Pham T, Koç E, Ghanbarzadeh A and Otri S. Optimisation of the weights of multilayered perceptrons using the Bees algorithm. In: Proceedings of 5th International Symposium on Intelligent Manufacturing Systems, Turkey; 2006.

26. Pham DT, Soroka AJ, Ghanbarzadeh A, Koç E, Otri S and Packianather M. Optimising neural networks for identification of wood defects using the Bees. In: Proceedings 2006 IEEE International Conference on Industrial Informatics. Singapore; 2006. http://dx.doi.org/10.1109/INDIN.2006.275855

27. Rosen BE and Goodwin JM. Optimizing neural networks using very fast simulated annealing, Neural, Parallel and Scientific Computations. 1997; 5(3):383-392.

28. Cardoso MF, Salcedo RL, Azevedo SF and Barbosa D. A simulated annealing approach to the solution of minlp problems. Computers \& Chemical Engineering. 1997; 21(12):1349-1364. http://dx.doi.org/10.1016/S0098-1354(97)00015-X

29. Simon D. Biogeography-based optimization. IEEE Transactions on Evolutionary Computation. 2008; 12(6) :702-713. http:// dx.doi.org/10.1109/TEVC.2008.919004

30. Roy PK, Ghoshal SP and Thakur SS. Biogeography based optimization for multiconstraint optimal powerflow with emission and non-smooth cost function. Expert Systems with Applications. 2010; 37(12): 8221-8228. http://dx.doi. org/10.1016/j.eswa.2010.05.064

31. Gandomi AH, She Yang X and Alavi AH. Mixed variable structural optimization using Firefly Algorithm. Computers \& Structures. 2011; 89(23-24):2325-2336. http://dx.doi. org/10.1016/j.compstruc.2011.08.002

32. Tian Y, Gao W and Yan S. An Improved Inertia Weight Firefly Optimization Algorithm and Application. English and Communication Technology. 2012; 1:64-68.

33. Ayan K. and Click U. Artificial bee colony algorithm solution for optimal reactive power flow. Applied Soft Computing. 2012; 12:1477-1482. http://dx.doi.org/10.1016/j.asoc.2012.01.006

34. Karaboga D and Basturk B. On the performance of artificial bee colony (ABC) algorithm. Applied Soft Computing. 2008; 8:687-697. http://dx.doi.org/10.1016/j.asoc.2007.05.007

35. Atashpaz-Gargari E and Lucas C. Imperialist competitive algorithm: an algorithm for optimization inspired by imperialistic competition. In: IEEE Congress on Evolutionary Computation. Singapore; 2007.

36. Abdollahi M, Isazadeh A and Abdollahi D. Imperialist competitive algorithm for solving systems of nonlinear equations. Computers and Mathematics with Applications. 2013; 65:1894-1908. http://dx.doi.org/10.1016/j.camwa.2013.04.018

37. Yousefi M, Darus AN and Mohammadi H. An imperialist competitive algorithm for optimal design of plate-fin heat exchangers. International Journal of Heat and Mass Transfer. 2012; 55(11-12):3178-3185. http://dx.doi.org/10.1016/j. ijheatmasstransfer.2012.02.041

38. Nazari-Shirkouhi S, Eivazy H, Ghodsi R, Rezaie K and AtashpazGargari E. Solving the integrated product mix-outsourcing problem using the Imperialist Competitive Algorithm. Expert Systems with Applications. 2010; 37(12):7615-7626. http:// dx.doi.org/10.1016/j.eswa.2010.04.081

39. Taher SA, Hajiakbari Fini M and Falahati Aliabadi S. Fractional order PID controller design for LFC in electric power systems using imperialist competitive algorithm. Ain Shams Engineering Journal. 2013. In press. http://dx.doi. org/10.1016/j.asej.2013.07.006

40. Moradi $\mathrm{H}$ and Zandieh M. An imperialist competitive algorithm for a mixed-model assembly line sequencing problem. Journal of Manufacturing Systems. 2013; 32(1): 46-54. http://dx.doi. org/10.1016/j.jmsy.2012.05.001

41. Nourmohammadi A, Zandieh M and Tavakkoli-Moghaddam R. An imperialist competitive algorithm for multi-objective U-type assembly line design. Journal of Computational Science. 2013. In press. http://dx.doi.org/10.1016/j.jocs.2012.09.001

42. Talatahari S, Farahmand Azar B, Sheikholeslami R and Gandomi AH. Imperialist competitive algorithm combined with chaos for global optimization. Communications in Nonlinear Science and Numerical Simulation. 2012; 17(3): 1312-1319. http://dx.doi.org/10.1016/j.cnsns.2011.08.021

43. Mozafari H, Abdi B and Ayob A. Application of imperialist competitive algorithm for optimizing a thin resistant interphase. Procedia Technology. 2012; 1:187- 193. http://dx.doi. org/10.1016/j.protcy.2012.02.035

44. Murty BS, Mohan Rao M and Ranganathan S. Milling maps and amorphization during mechanical alloying. Acta Metallurgica et Materialia. 1995; 43:2443-2450. http://dx.doi. org/10.1016/0956-7151(94)00402-1

45. Takacs L. Self-sustaining reactions induced by ball milling. Progress in Materials Science. 2002; 47(4): 355-364. http:// dx.doi.org/10.1016/S0079-6425(01)00002-0

46. Sharifi EM, Karimzadeh F and Enayati MH. Synthesis of titanium diboride reinforced alumina matrix nanocomposite by mechanochemical reaction of $\mathrm{Al}_{-} \mathrm{TiO}_{2}-\mathrm{B}_{2} \mathrm{O}_{3}$. Journal of Alloys and Compounds. 2010: 502(2): 508-512. http://dx.doi. org/10.1016/j.jallcom.2010.04.207 